\title{
Mangiferin induces radiosensitization in glioblastoma cells by inhibiting nonhomologous end joining
}

\author{
FAGUANG MU ${ }^{1 *}$, TING LIU $^{2 *}$, HANRUI ZHENG ${ }^{2,3^{*}}$, XIAOFANG XIE $^{2^{*}}$, TIANTIAN LEI ${ }^{2}$, \\ XIA HE ${ }^{4}$, SUYA DU $^{5}$, RONGSHENG TONG ${ }^{4}$ and YI WANG ${ }^{4}$ \\ ${ }^{1}$ Department of Pediatrics, Sichuan Academy of Medical Science \& Sichuan Provincial People's Hospital, \\ Chengdu, Sichuan 610072; ${ }^{2}$ School of Medicine, University of Electronic Science and Technology of China, \\ Chengdu, Sichuan 610054; ${ }^{3}$ Department of Pharmacy, Sichuan University Affiliated West China Hospital, Chengdu, \\ Sichuan 610041; ${ }^{4}$ Personalized Drug Therapy Key Laboratory of Sichuan Province, Department of Pharmacy, \\ Sichuan Academy of Medical Science \& Sichuan Provincial People's Hospital, Chengdu, Sichuan 610072; \\ ${ }^{5}$ Department of Clinical Pharmacy, Chengdu Military General Hospital, Chengdu, Sichuan 610083, P.R. China
}

Received March 26, 2018; Accepted September 3, 2018

DOI: $10.3892 / o r .2018 .6756$

\begin{abstract}
Although surgery and high-dose radiotherapy have been the standard treatments for glioblastoma multiforme (GBM), these therapies are palliative, due to the high risk of local relapse. Emerging evidence has demonstrated that DNA double-strand break (DSB) repair serves a critical role in resistance to radiotherapy. Previous studies have revealed that mangiferin possesses anti-neoplastic effects on human lung adenocarcinoma and ovarian cancer. The present study aimed to investigate the role of mangiferin in radio-sensitivity inhuman GBM. Through in vitro experiments, decreased proliferation and increased DNA damage were observed in cells pretreated with mangiferin following radiation. Further study of the repair pathway indicated that mangiferin inhibits the non-homologous end-joining (NHEJ) DSB repair pathway. Furthermore, studies on key proteins in the NHEJ DSB repair pathway revealed that mangiferin inhibited the phosphorylation of serine-protein kinase ATM, TP53-binding protein 1 and $\gamma$-histone $\mathrm{H} 2 \mathrm{AX}(\gamma-\mathrm{H} 2 \mathrm{AX})$. In addition, observations on the average percentages of $\gamma-\mathrm{H} 2 \mathrm{AX}$-positive cells and the average number of $\gamma-\mathrm{H} 2 \mathrm{AX}$ foci per cell suggested that treatment with mangiferin decreased the number of $\gamma$-H2AX foci
\end{abstract}

Correspondence to: Dr Yi Wang or Dr Rongsheng Tong, Personalized Drug Therapy Key Laboratory of Sichuan Province, Department of Pharmacy, Sichuan Academy of Medical Science \& Sichuan Provincial People's Hospital, 32 West Ring Road, Chengdu, Sichuan 610072, P.R. China

E-mail: w_yi@yahoo.com

E-mail: tongrs@126.com

${ }^{*}$ Contributed equally

Key words: glioblastoma multiforme, mangiferin, non-homologous end-joining, homologous recombination in GBM cells following radiation. However, mangiferin selectively inhibited DSB repair in GBM cells, and was not able to trigger DSB repair inhibition in normal neuronal Schwann cells. Through in vivo tumor-bearing mouse experiments, a smaller tumor volume, decreased tumor weight and prolonged life span were observed in mice treated with mangiferin following radiation. Therefore, xenograft GBM models clearly demonstrated that treatment with mangiferin treatment may increase tumor sensitivity to radiotherapy. Taken together, as demonstrated by in vivo and in vitro data, mangiferin may be a potential novel therapeutic drug for improving the radiation sensitivity of glioblastoma.

\section{Introduction}

It has been widely acknowledged that glioblastoma multiforme (GBM), characterized by its poor 2-year survival rate and high mortality rate, is the most aggressive and malignant subtype of glioma (1). Canonical therapy for GBM includes surgical resection of tumors followed by radiotherapy (2). However, these therapies remain largely palliative as the majority of patients relapse within a year of their initial operation (3). Previous studies have indicated that the activation of cell survival pathways following ionizing radiation (IR) contributes to the induction of recurrence (4). In addition, aberrations in tumor suppressor genes also serve critical roles in tumor relapse (5). Notably, the induction of recurrence following radioresistance is commonly associated with the activation of DNA double strand break (DSB) repair $(6,7)$. There exist two major pathways for DNA DSB repair, which are nonhomologous end-joining (NHEJ) and homologous recombination (HR). It has been demonstrated that IR-induced DSB repair is predominantly through the NHEJ pathway, which is an intrinsically error-prone pathway and occurs in all phases of the cell cycle (8). A number of proteins influence NHEJ, including the DNA-dependent protein kinase catalytic subunit, the $\mathrm{Ku} 70 / 80$ heterodimer, serine-protein kinase ATM(ATM), $\gamma$-histone $\mathrm{H} 2 \mathrm{AX}(\gamma$-H2AX), and TP53-binding protein 1 
(53BP1) (9-12). Studies have demonstrated that cells deficient in the NHEJ-associated proteins mentioned above are hypersensitive to IR (13). Therefore, a novel therapeutic drug targeting the NHEJ pathway may be a promising radiosensitization approach for the treatment of glioblastoma following IR.

Mangiferin, 1,3,6,7-tetrahydroxyxanthone-C2- $\beta$ - $D$-gluco side, is isolated from the leaves, stem barks, fruit peels and roots of Mangiferina indica (14). Known as an antioxidant, anti-diabetic and anti-inflammatory compound (15-18), mangiferin also exhibits anti-neoplastic effects in lung cancer (19-21), colon cancer $(20,22)$, leukemia $(19,23-26)$ and ovarian cancer (27). A previous study demonstrated the decreased proliferation and increased apoptosis induced by mangiferin in glioma cells via the induction of microRNA-15b and the inhibition of matrix metalloproteinase- 9 expression (28). Further studies on mangiferin demonstrated that it suppresses the invasiveness of glioma cells by inhibiting the activation of the phosphatidylinositol 3-kinase/RAC- $\alpha$ serine/threonine-protein kinaseand mitogen-activated protein kinase signaling pathways (29). Additionally, mangiferin enhances recognition memory by increasing neurotrophin and cytokine levels (30). However, to the best of our knowledge, there are no data on whether mangiferin is able to improve radiosensitivity in GBM cells. In the present study, it was demonstrated that treatment with mangiferin was able to sensitize U-87 MG and U-118MG cells to IR. As it remained unclear which repair pathways were the most relevant targets of mangiferin in GBM following IR, the two pathways were examined, the radiosensitization effect of mangiferin was observed to be mediated by inhibition of the NHEJ pathway. Taken together, these findings demonstrated a novel function of mangiferin by inhibiting NHEJ of DSBs generated by IR. Therefore, the present study on mangiferin offered a potential novel strategy by which to increase the sensitivity of glioblastoma to radiotherapy.

\section{Materials and methods}

Reagents. Mangiferin was purchased from Shanghai PureOne Technology (Shanghai, China). The purity of mangiferin was $>95 \%$, as demonstrated by high-performance liquid chromatography. Dulbecco's modified Eagle's medium (DMEM), fetal bovine serum (FBS) and $0.25 \%$ trypsin were purchased from Gibco (Thermo Fisher Scientific, Inc., Waltham, MA, USA). MTT (cat. no. M5655), dimethyl sulfoxide (DMSO; cat. no. D2650), $0.25 \%$ trypsin solution (cat. no. T4049), bovine serum albumin (BSA; cat. no. V900933), DAPI (cat. no. D9542), paraformaldehyde (PFA; cat. no. 16005), HEPES (cat. no. H3375), Triton X-100 (cat. no. H9284), $2 \mathrm{mM}$ sodium orthovanadate (cat. no. S6508), sodium fluoride (cat. no. S7920), $1 \mathrm{mM}$ edetic acid (cat. no. E9884), phenylmethylsulfonyl fluoride (PMSF; cat. no. 78830), aprotinin (cat.no.A11530), leupeptin (cat.no.L2884), penicillin and streptomycin (cat. no. V900929), and L-glutamine (cat. no. G3126) were purchased from Sigma-Aldrich (Merck KGaA, Darmstadt, Germany). The Annexin V-fluorescein isothiocyanate (FITC)/propidium iodide (PI) apoptosis detection kit (cat. no. C1063) was purchased from Beyotime Institute of Biotechnology (Haimen, China).
Cell culture, cell survival and DNA damage assay. The human glioblastoma of unknown origin cell lineU-87 MG (cat. no. HTB-14) and human glioblastoma cell line U-118 MG (cat. no. HTB-15) were obtained from the American Type Culture Collection (ATCC; Manassas, VA, USA). Short tandem repeat (STR) DNA profiling of U-87 MG cells and U-118 MG cells was performed using the Cell ID System (cat. no. G9500; Promega Corporation, Madison, WI, USA), and the products were analyzed using an ABI 3130 Genetic Analyzer (Applied Biosystems; Thermo Fisher Scientific, Inc.). Although the U-87 MG cell line from the ATCC is not the original cell line from the University of Uppsala (31), and the U-118 MG and U138 lines exhibit cross contamination (32), these cell lines remain widely used in the study of glioblastoma $(33,34)$. Furthermore, U-87 MG cells may be engineered with various expression vectors. Thus, it was decided to use the U87 and U-118 MG cells from the ATCC in the present study for the in vitro and in vivo experiments. A rat immortalized neuronal Schwann cell line (cat. no. CRL-2765) was also purchased from the ATCC. Cells were cultured in DMEM containing 10\% FBS, $100 \mu \mathrm{g} / \mathrm{ml}$ streptomycin, $100 \mathrm{U} / \mathrm{ml}$ penicillin and $0.03 \%$ L-glutamine and maintained at $37^{\circ} \mathrm{C}$ with $5 \% \mathrm{CO}_{2}$ in a humidified atmosphere.

Cells in the logarithmic growth phase were seeded in a 96-well plate $\left(3 \times 10^{4}\right.$ cells/well) and incubated at $37^{\circ} \mathrm{C}$ for $24 \mathrm{~h}$. Mangiferin $(25 \mu \mathrm{g} / \mathrm{ml})$ and control solvent (DMSO) were added and incubated for $48 \mathrm{~h}$ (28). The cells were irradiated with a calibrated Shepherd \& Associates Mark I self-shielded ${ }^{137} \mathrm{Cs}$ rirradiator (JL Shepherd \& Associates Inc., San Fernando, CA, USA), at a dose of $1.84 \mathrm{~Gy} / \mathrm{min}$ for $2 \mathrm{~min}$ and $43 \mathrm{sec}$. As a control, mock irradiation (0 Gy) was performed by placing the plates containing the cells in the irradiator for the designated time period without turning on the machine (35). For dose-dependent and time course study, different dosage of mangiferin $(12.5,25,50$ and $100 \mu \mathrm{g} / \mathrm{ml})$ were added and incubated for $12,24,36$ and $48 \mathrm{~h}$, respectively. A total of $0.05 \mathrm{mg}(10 \mu \mathrm{l} \mathrm{of} 5 \mathrm{mg} / \mathrm{ml})$ MTT was added to each well and incubated at $37^{\circ} \mathrm{C}$ for $4 \mathrm{~h}$; the medium was removed and termination buffer (SDS- $\mathrm{HCl}$ ) was added to each well. The absorbance at $570 \mathrm{~nm}$ was measured with a spectrophotometer (Model 3550 Microplate Reader; Bio-Rad Laboratories, Inc., Hercules, CA, USA). Cell viability was calculated as follows: Cell viability $(\%)=$ [optical density (OD) $570 \mathrm{~nm}$ (drug)/OD $570 \mathrm{~nm}$ (control)] x 100. Cellular apoptosis was measured with the Annexin V-FITC/PI apoptosis detection kit. In brief, cells were harvested with $0.25 \%$ trypsin and washed twice with cold PBS. A total of $1 \times 10^{5}$ cells were resuspended in $1 \mathrm{X}$ binding buffer, and incubated with $5 \mu \mathrm{l}$ FITC-conjugated Annexin V and $5 \mu \mathrm{l}$ PI for $15 \mathrm{~min}$ at room temperature in the dark. Samples were analyzed using a FACSAria II machine (BD Biosciences, San Jose, CA, USA). Data were analyzed with Cell Quest Pro software (version 5.2.1; BD Biosciences).

8-Hydroxy-2'-deoxyguanosine $(8-\mathrm{OHdG})$ is a modified nucleotide base and by-product of DNA damage that is excreted upon DNA repair (36). By measuring the levels of 8-OHdG, DNA damage percentages were determined using a commercial ELISA kit (cat. no. ADI-EKS-350; Enzo Life Sciences, Inc., Farmingdale, NY, USA). 
Immunofluorescent staining. U-87 MG, U-118 MG and Schwann cells were seeded into a 6-well culture plate at a density of $4 \times 10^{5}$ cells/well and cultured for $24 \mathrm{~h}$. Following treatment with mangiferin or control solvent, cells were exposed to 5-Gy radiation using the Mark $\mathrm{I}^{137} \mathrm{Cs}$ irradiator. Following irradiation, immunofluorescent staining of $\gamma-\mathrm{H} 2 \mathrm{AX}$ was performed as previously described (35). Cells were fixed with $4 \%$ PFA for $30 \mathrm{~min}$ at room temperature, and permeabilized with $1 \%$ Triton X-100. Following blocking with 5\% BSA for $1 \mathrm{~h}$ at room temperature, cells were incubated with rabbit polyclonal $\gamma$-H2AX (phospho-S139) antibody (1:100 dilution; cat. no. ab11174, Abcam, Cambridge, MA, USA) overnight at $4^{\circ} \mathrm{C}$. The cells were incubated with fluorescein isothiocyanate-conjugated goat anti-rabbit immunoglobulin (Ig) G polyclonal antibody (1:500 dilution; cat. no. 111-095-003, Jackson ImmunoResearch Laboratories, Inc., West Grove, PA, USA) for $2 \mathrm{~h}$ at room temperature. Following staining with DAPI, cells were washed and analyzed immediately under a fluorescence microscope (x200 magnification; Olympus Corporation, Tokyo, Japan). At least 500 cells were counted per slide, and cells containing $>10$ foci were scored as positive.

NHEJ/HR I-SceI reporter assay. In the NHEJ/HR I-SceI reporter assay, green fluorescent protein (GFP) expression was quantified (by flow cytometry) in U87-DRGFP cells transfected with an I-SceI plasmid as previously described $(37,38)$. In brief, a single DSB was generated in the plasmid substrate pEGFP-N1 (Addgene, Inc., Cambridge, MA, USA) containing an NHEJ or HR reporter cassette by cleavage between the promoter and GFP reporter gene with I-SceI (cat. no. R0694; New England BioLabs, Inc., Ipswich, MA, USA) or HindIII (cat. no. R0104; New England BioLabs, Inc.,) restriction enzymes. The linear products were purified using a gel purification kit (cat. no. DP209; Tiangen Biotech Co., Ltd., Beijing, China). Serum-starved (overnight) U-87 MG cells were transfected with $1 \mu \mathrm{g}$ NHEJ reporter constructor $2 \mu \mathrm{g}$ HR reporter construct, and $0.1 \mu \mathrm{g}$ pDsRed-N1 as the internal control. Cells were harvested $48 \mathrm{~h}$ subsequently. The percentages of GFP-positive cells (NHEJ or HR-repaired cells) were quantitated using a FACSAria II machine (BD Biosciences). For each assay, $1 \times 10^{5}$ cells were processed and data were analyzed with Cell Quest Pro software (Version 5.2.1; BD Biosciences).

Western blot analysis. U-87 MG cells and U-118 MG cells were treated with $50 \mu \mathrm{M}$ mangiferin or DMSO for $48 \mathrm{~h}$, and the cells were exposed to 5-Gy radiation using the Mark I ${ }^{137} \mathrm{Cs}$ irradiator. Adherent and floating cells were collected. The cell pellets were resuspended with lysis buffer and lysed at $4^{\circ} \mathrm{C}$ for $15 \mathrm{~min}$. The lysis buffer consisted of $50 \mathrm{mM}$ HEPES (pH 7.4), $1 \%$ Triton X-100, $2 \mathrm{mM}$ sodium orthovanadate, $100 \mathrm{mM}$ sodium fluoride, $1 \mathrm{mM}$ edetic acid, $1 \mathrm{mM}$ PMSF, $10 \mathrm{mg} / 1$ aprotinin and $10 \mathrm{mg} / \mathrm{l}$ leupeptin. Following 12,000 x g centrifugation for $15 \mathrm{~min}$ at $4^{\circ} \mathrm{C}$, the protein content of the supernatant was determined by Bradford protein assay (cat. no. P0006; Beyotime Institute of Biotechnology). Equal amounts of the total protein $(10 \mu \mathrm{g})$ were separated on $4-12 \%$ NuPAGE Bis-Tris gels (cat. no. NP0327BOX; Life Technologies; Thermo Fisher Scientific, Inc.) and transferred to PVDF membranes (cat. no. ISEQ00010; EMD Millipore, Billerica, MA, USA). The membranes were soaked in blocking buffer (5\% BSA; cat. no. V900933; Sigma-Aldrich; Merck KGaA) at room temperature for $1 \mathrm{~h}$, and incubated with primary antibodies at $4^{\circ} \mathrm{C}$ overnight. The following primary antibodies were used in this study. Rabbit polyclonal 53BP1 antibody (1:1,000 dilution; cat. no. ab36823), rabbit polyclonal phospho-53BP1 (S25) antibody (1:1,000 dilution; cat. no. ab70323), mouse monoclonal phospho-ATM (S1981) antibody (1:1,000 dilution; cat. no. ab19304), rabbit polyclonal $\gamma$-H2AX (phosphor-S139) antibody (1:1,000 dilution; cat. no. ab11174) were purchased from Abcam. Mouse monoclonal $\beta$-actin antibody (1:5,000 dilution; cat. no. sc-47778) was purchased from Santa Cruz Biotechnology, Inc. (Dallas, TX, USA). Following incubation with specific primary antibodies, the membranes were washed and incubated with the corresponding secondary antibodies at room temperature for $2 \mathrm{~h}$. For the secondary antibodies, horseradish peroxidase (HRP)-conjugated goat anti-mouse $\operatorname{IgG}$ polyclonal antibody (1:5,000 dilution; cat. no. 115-035-003) and HRP-conjugated goat anti-rabbit polyclonal $\operatorname{IgG}(1: 5,000$ dilution; cat. no. 111-035-003) were purchased from Jackson ImmunoResearch Laboratories, Inc. The membranes were washed and visualized via enhanced chemiluminescence (cat. no. 345818; EMD Millipore).

Tumor xenograft study. To establish tumor xenografts, $5 \times 10^{6}$ U-118 MG cells were injected into BALB/c nude male mice (5-6 weeks old; 16-18 g body weight; Affiliated Laboratory Animal Center of Sichuan Academy of Medical Science and Sichuan Provincial People's Hospital, Chengdu, China). Following implantation, the tumors were allowed to grow to a size of $100-550 \mathrm{~mm}^{3}$. No mouse bearing multiple tumors was identified in the present study. Furthermore, the largest diameter exhibited by a single subcutaneous tumor was $1.1 \mathrm{~cm}$. The mice were randomly divided into 4 groups ( $n=80$ in total and $n=20$ per group) as follows: i) The control group, in which mice with U-118 MG-derived tumors were left untreated; ii) the IR group, in which mice received 25-Gy IR following tumor formation by U-118 MG cells; iii) the mangiferin group, in which mice were intraperitoneally administered with $5 \mathrm{mg} / \mathrm{kg}$ mangiferin following tumor formation by U-118 MG cells; and iv) the IR+mangiferin group, in which mice were intraperitoneally administered with $5 \mathrm{mg} / \mathrm{kg}$ mangiferin and subjected to 25-Gy IR following tumor formation by U-118 MG cells. Following treatment, mouse body weights were measured every day. On day 20, 10 mice in each group were sacrificed, and 10 mice in each group were used for survival analysis. The subcutaneous tumors were removed from the sacrificed mice and weighed. Meanwhile, the volume of the tumors was determined in three dimensions with Vernier calipers, according to the following formula: Tvol $=$ length $\mathrm{x}$ width $\mathrm{x}$ depth $\mathrm{x} 0.5$. Animal handling was approved by the Ethics Committee of Sichuan Academy of Medical Science and Sichuan Provincial People's Hospital, and all animals were kept in a $12 \mathrm{~h}$ light/dark cycle with free access to water and food $\left(26^{\circ} \mathrm{C}\right.$ and $40-60 \%$ humidity), which is in accordance with individual ventilated cage requirements at the Sichuan Academy of Medical Science and Sichuan Provincial People's Hospital.

Statistical analysis of the data. The experiments were repeated three times, and all data are expressed as the mean \pm standard 
error of the mean from at least three independent experiments. Data analysis was performed using GraphPad Prism 5.0 software (GraphPad Software, Inc., La Jolla, CA, USA). Statistical significance between multiple groups was determined by one- or two-way analysis of variance with a Bonferroni post hoc test, and between two groups using a Student's t-test. Survival analyses were carried out using Kaplan-Meier curves. $\mathrm{P}<0.05$ was considered to indicate a statistically significant difference.

\section{Results}

Mangiferin inhibits cell viability following IR. Based on a previous study on mangiferin $(21,27)$, it was hypothesized that mangiferin may increase the sensitivity of glioblastoma cells to radiation. Therefore, to substantiate this hypothesis and to examine the inhibitory role of mangiferin in GBM cells following IR, MTT assays were performed on U-87 MG (Fig. 1A) and U-118 MG cells (Fig. 1B). As predicted, the proliferation rates of U-87 MG cells treated with $25 \mu \mathrm{g} / \mathrm{ml}$ mangiferin following5-Gy IR were decreased significantly compared with those of the mock-treated cells (Fig. 1A), indicating that mangiferin may be a potential radiosensitive agent in the treatment of GBM following IR. Although the U87 cell line from ATCC is not the original cell line from the University of Uppsala (31), the cells remain widely used in the study of glioblastoma $(33,34)$. To further ascertain the potential inhibitory role of mangiferin following IR, the radiosensitizing potential of mangiferin in U-118 MG cells was also determined. As presented in Fig. 1B, the proliferation rates of U-118 MG cells were greatly inhibited following combined treatment with mangiferin and IR. To further assess whether mangiferin was able to radiosensitize GBM cells by inhibiting DNA repair, a radiation survival assay was performed to assess this in a dose and time-dependent manner. Consistent with the proliferation data (Fig. $1 \mathrm{~A}$ and $\mathrm{B}$ ), with 5 Gy radiation, U-87 MG cells (Fig. 1C) and U-118 MG cells (Fig. 1D) exhibited marked sensitivity to radiation following treatment with mangiferin. Notably, this radiosensitization was dose-dependent, meaning that a lesser degree of sensitization was observed in cells treated with lower concentrations of mangiferin. Furthermore, this radiosensitization was also time-dependent. On the basis of these experiments, a concentration of $25 \mu \mathrm{g} / \mathrm{ml}$ mangiferin was used for the subsequent experiments. Taken together, these results suggested that mangiferin may enhance the radiosensitivity of glioblastoma cells to radiation, and therefore inhibit the viability of cells following radiation.

Mangiferin inhibits DNA damage repair via the NHEJ pathway. To examine the mechanism of mangiferin-induced radiosensitivity in glioblastoma cells, the present study examined whether mangiferin was able to increase the DNA damage percentages in GBM cells following IR. As indicated by Fig. 2A (U-87 MG cells) and Fig. 2B (U-118 MG cells), mangiferin-treated GBM cells exhibited increased numbers of DNA damage percentages, which correlated with the high degree of radiosensitization observed in Fig. 1. These observations indicated that mangiferin possibly mediated radiosensitization through the inhibition of DNA damage repair.
Since in eukaryotic cells there exist two major DSB repair pathways following radiation, one of which is the fast and efficient, although error-prone, NHEJ DNA repair pathway. The other is error-free HR, which is considered to be a more accurate mechanism for DSB repair as it uses homologous sequences for repair synthesis. However, as there is competition and crosstalk between these two repair pathways (39), the present study subsequently investigated by which pathway mangiferin inhibited DSB repair and thus induced the limited proliferation following radiation. Notably, treatment with mangiferin resulted in NHEJ repair defects in cells that were more severe than those in the control solvent cells (Fig. 3A). Statistical analysis of NHEJ percentages further confirmed this (Fig. 3B). Therefore, NHEJ repair was significantly inhibited by mangiferin. In contrast to the inhibitory effects of mangiferin on NHEJ repair, pretreatment of cells with mangiferin led to decreased HR repair percentages (Fig. 4A), although this decrease was not statistically significant ( $P>0.05$; Fig. 4B).

To further determine the mechanisms of mangiferin-mediated inhibition of NHEJ repair in GBM cells, the present study investigated the phosphorylation levels of ATM, 53BP1 and $\gamma-\mathrm{H} 2 \mathrm{AX}$. It was identified that mangiferin attenuated the activation of ATM, 53BP1 and $\gamma-\mathrm{H} 2 \mathrm{AX}$ in U-87 MG cells. Similarly, the phosphorylation of ATM, 53BP1 and $\gamma-\mathrm{H} 2 \mathrm{AX}$ was also markedly impaired by pretreatment with mangiferin in U-118 MG cells (Fig. 5). Collectively, these data suggested that the radiosensitization effect of mangiferin was due to its inhibition of the NHEJ repair pathway.

Mangiferin decreases the number of $\gamma-H 2 A X$ foci. To validate the findings on mangiferin-mediated inhibition of NHEJ repair, immunocytochemistry staining of U-87 MG and U-118 MG cells and assessed the repair percentages by investigating the number of $\gamma$-H2AX foci (Fig. 6). Immunocytochemistry analysis revealed that pretreatment with mangiferin decreased the percentages of $\gamma$-H2AX foci (Fig. 6A). Notably, statistical analysis of the average percentages of $\gamma-\mathrm{H} 2 \mathrm{AX}$-positive $\mathrm{U}-87$ MG cells (Fig. 6B) and U-118 MG cells (Fig. 6D) clearly indicated that pretreatment with mangiferin decreased the number of $\gamma$-H2AX foci in cells. Similar to the data on $\gamma$-H2AX-positive cell percentages, the average numbers of $\gamma$-H2AX foci per cell were significantly decreased in U-87 MG cells (Fig. 6C) and U-118 MG cells (Fig. 6E). These results clearly indicated that mangiferin was able to potently inhibit NHEJ, resulting in DSB repair defects by decreasing the number of $\gamma$-H2AX foci in GBM cells.

Mangiferin does not inhibit DSB repair in Schwann cells. To investigate whether mangiferin was able to induce the inhibition of DSB repair in neuronal cells, DSB repair was examined in rat immortalized neuronal Schwann cells. In Fig. 7A, cells pretreated with mangiferin and control solvent exhibited comparatively similar numbers of $\gamma-\mathrm{H} 2 \mathrm{AX}$ foci. Statistical analysis of the average percentages of $\gamma$-H2AX-positive cells (Fig. 7B) and average numbers of $\gamma$-H2AX foci per cell (Fig. 7C) clearly demonstrated that pretreatment with mangiferin was not able to attenuate DSB repair in Schwann cells. Further analysis of the DNA damage percentages also indicated that pretreatment with mangiferin was not able to inhibit DSB repair in rat neuronal Schwann cells. These data 

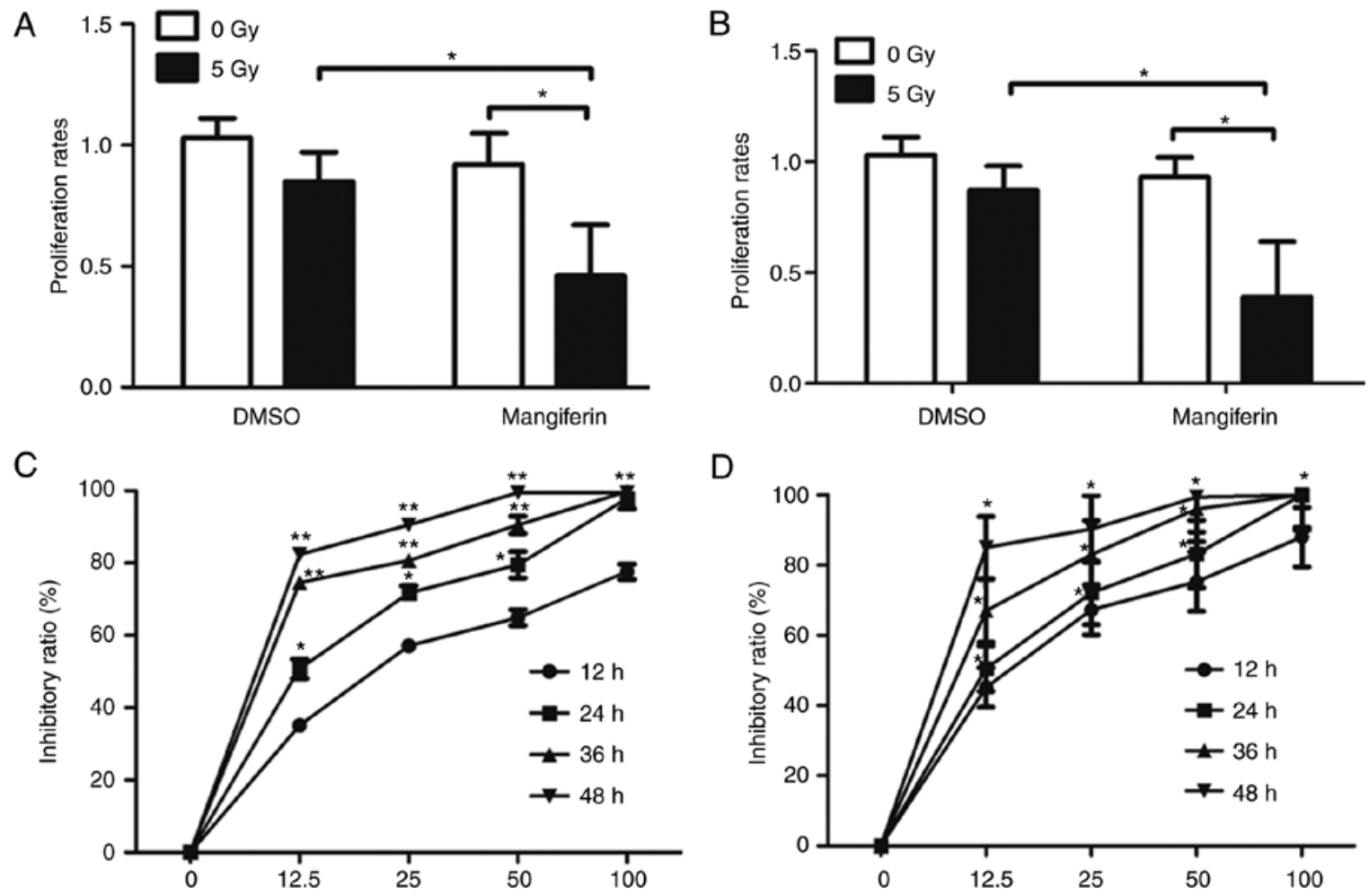

Figure 1. Mangiferin inhibits cell viability following irradiation. (A) Proliferation rates of U-87 MG cells. (B) Proliferation rates of U-118 MG cells. "P<0.05. (C) Time course and dose-dependence assay of U-87 MG cells treated with mangiferin following radiation. ${ }^{*} \mathrm{P}<0.05$ and ${ }^{* *} \mathrm{P}<0.01$ vs. respective $12 \mathrm{~h}$ groups by two-way ANOVA. (D) Time course and dose-dependence assay of U-118 MG cells treated with mangiferin following radiation. " $\mathrm{P}<0.05 \mathrm{vs}$. respective $12 \mathrm{~h}$ group by two-way ANOVA. Data are the mean \pm standard error of the mean from three independent experiments. ANOVA, analysis of variance; DMSO, dimethyl sulfoxide.
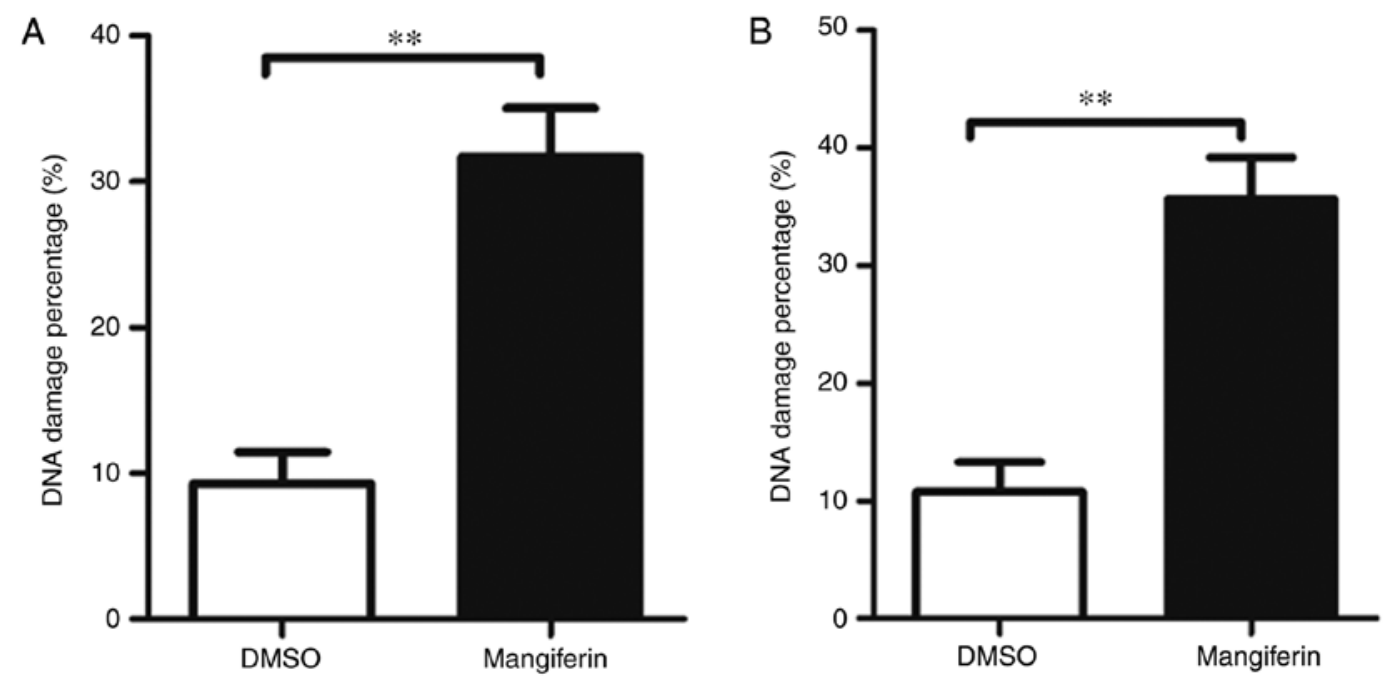

Figure 2. Mangiferin increases DNA damage percentages. (A) DNA damage percentages of U-87 MG cells treated with either mangiferin or DMSO following irradiation. (B) DNA damage percentages of U-118 MG cells treated with either mangiferin or DMSO following irradiation. ${ }^{* *} \mathrm{P}<0.01$. Data are the mean \pm standard error of the mean from three independent experiments. DMSO, dimethyl sulfoxide.

suggested that mangiferin selectively inhibited DSB repair in GBM cells, and was unable to trigger inhibition in normal neuronal cells.

Mangiferin increases radiosensitivity in vivo. Finally, to determine the effect of mangiferin on radiosensitivity in xenograft tumors, subcutaneous tumors were generated in nude mice using U-118 MG cells (Fig. 8). As presented in Fig. 8A, following treatment with IR and mangiferin, tumor-bearing mice exhibited gradually increased body weights. Subsequently, tumors from mangiferin and IR co-treated mice exhibited marked reductions in the tumor volume (Fig. 8C) and the tumor weight (Fig. 8D), demonstrating that treatment with mangiferin and IR was able to inhibit tumor growth 
A

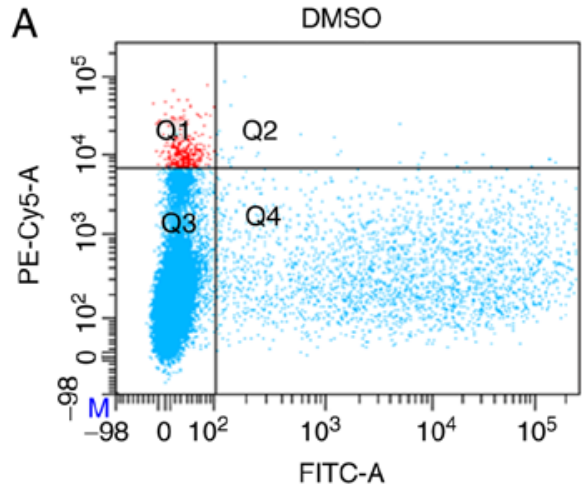

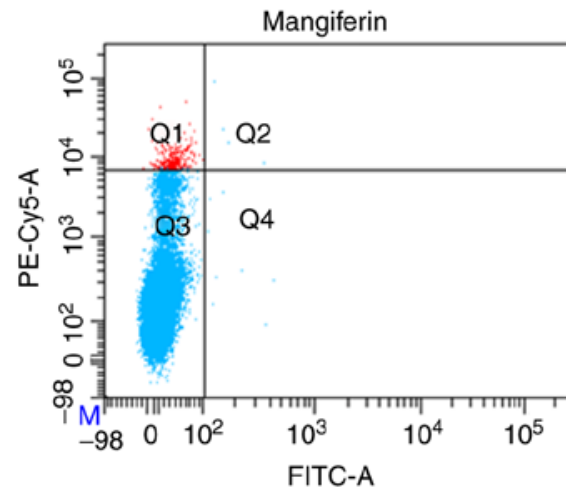

B

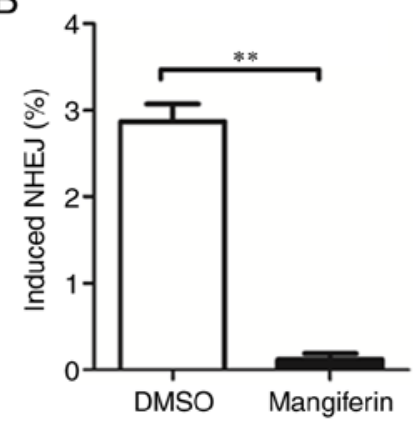

Figure 3. Mangiferin inhibits NHEJ repair. (A) Flow cytometry analysis of NHEJ repair in U-87 MG cells using an NHEJ-I SceI assay system. (B) Statistical analysis of NHEJ repair percentages of U-87 MG cells treated with either mangiferin or DMSO following irradiation. ${ }^{* *} \mathrm{P}<0.01$. Data are the mean \pm standard error of the mean from three independent experiments. FITC, fluorescein isothiocyanate; DMSO, dimethyl sulfoxide; NHEJ, non-homologous end-joining.

A

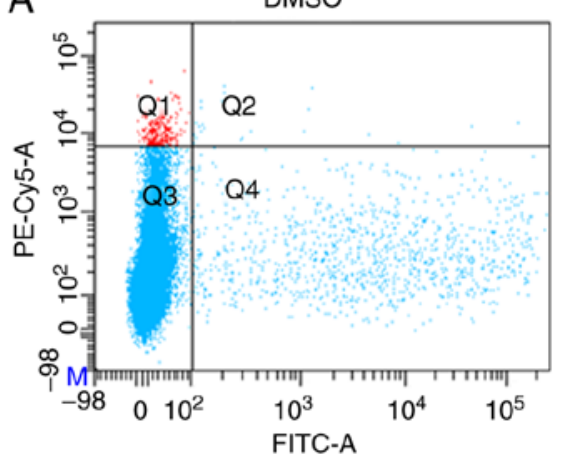

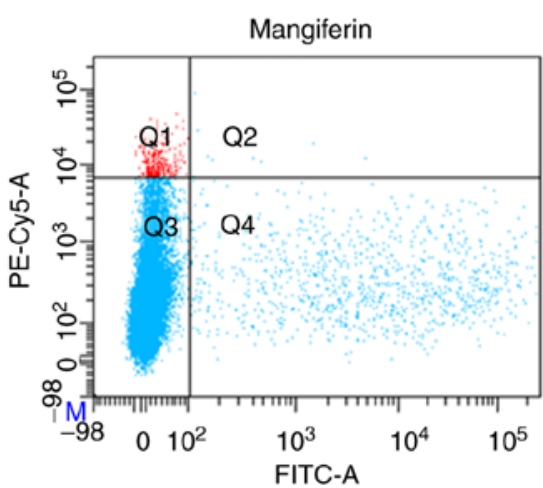

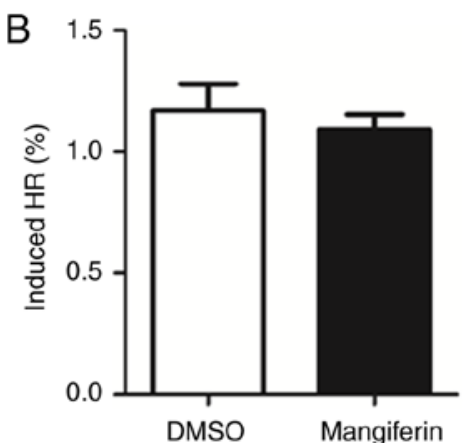

Figure 4. Mangiferin does not inhibit HR repair. (A) Flow cytometry analysis of HR repair in U-87 MG cells using an HR-I SceI assay system. (B) Statistical analysis of HR repair percentages of U-87 MG cells treated with either mangiferin or DMSO following irradiation. Data are the mean \pm standard error of the mean from three independent experiments. FITC, fluorescein isothiocyanate; DMSO, dimethyl sulfoxide; HR, homologous recombination.

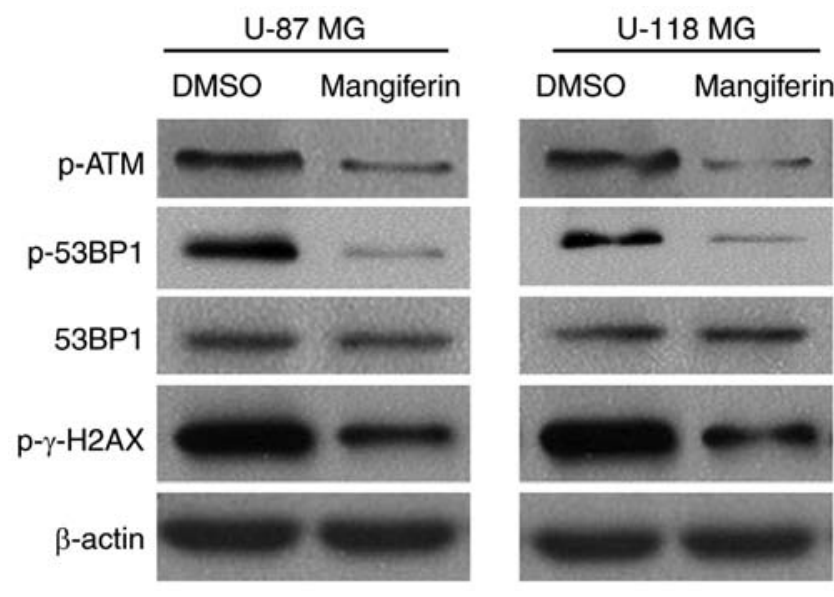

Figure 5. Mangiferin inhibits key proteins in non-homologous end-joining repair. Western blotting of phospho-ATM, phospho-53BP1, 53BP1, phospho- $\gamma$-H2AX and $\beta$-actin. Left, U-87 MG cells; right, U-118 MG cells. Images are representative of three independent experiments. ATM, serine-protein kinase ATM; 53BP1, TP53-binding protein $1 ; \gamma-\mathrm{H} 2 \mathrm{AX}$, $\gamma$-histone H2AX; p, phosphorylated; DMSO, dimethyl sulfoxide.

compared with IR alone, mangiferin alone and the normal saline control. Furthermore, the survival curve of xenograft mice clearly indicated that the irradiated mice pretreated with mangiferin had a comparatively prolonged life span (Fig. 8B). Taken together, these results demonstrated that pretreatment with mangiferin increased radiosensitivity in glioblastoma, in vitro and in vivo.

\section{Discussion}

With a poor 2-year survival rate, GBM is the most aggressive primary brain tumor in adults and the leading cause of mortality (40). Standard therapy for GBM includes surgical resection followed by radiotherapy and chemotherapy. However, GBM relapse rates remain high, likely due to the activation of DNA repair systems in cancer cells. Therefore, previous studies have focused on the improvement of radiosensitivity to IR by blocking DSB repair pathways (41-43). In the current study, markedly inhibited proliferation was observed with combined therapy of radiation and pretreatment with mangiferin, suggesting that mangiferin may be a potential radiosensitive agent. Furthermore, the improved sensitivity was dose- and time-dependent. Based on these observations, it was hypothesized that the improved radio sensitivity of GBM cells by pretreatment with mangiferin was mediate via the inhibition of DSB repair. Through analysis of DNA damage percentages, NHEJ and HR percentages, and $\gamma-\mathrm{H} 2 \mathrm{AX}$ foci numbers, the hypothesis that 
A

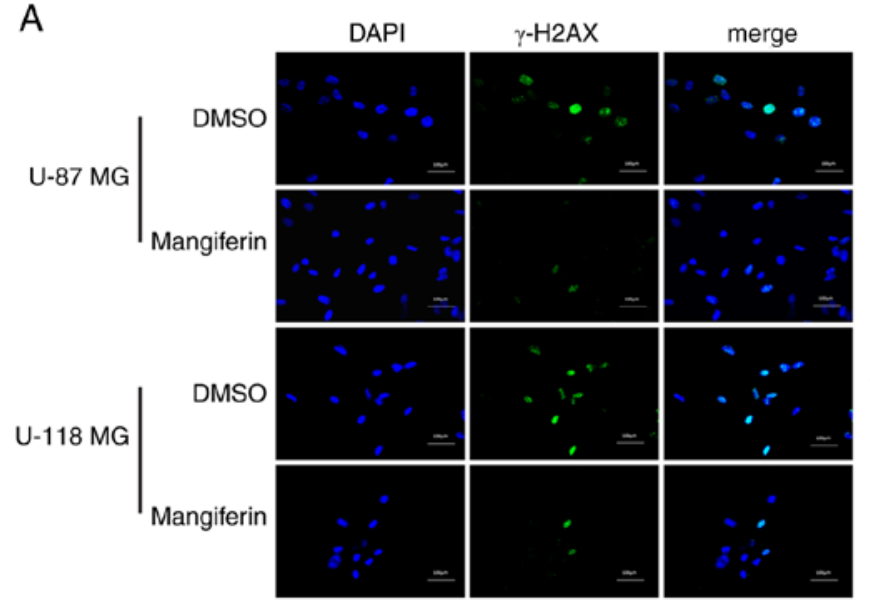

B

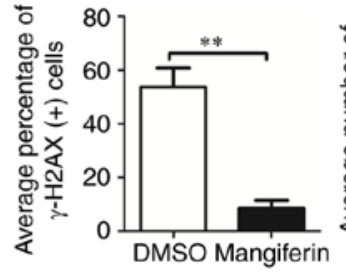

C

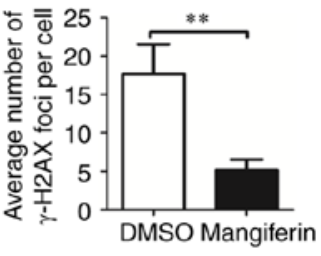

$\mathrm{E}$
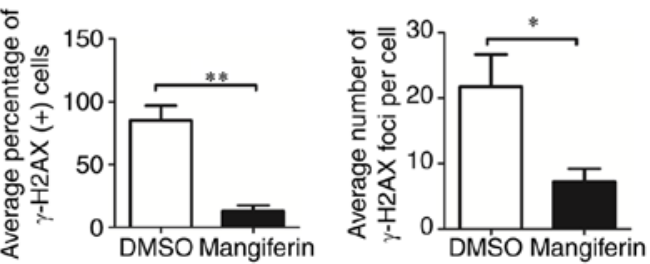

Figure 6. Mangiferin decreases the number of $\gamma-\mathrm{H} 2 \mathrm{AX}$ foci. (A) Immunofluorescent staining images of glioblastoma multiforme cells treated with either mangiferin or DMSO following irradiation. Green fluorescence, $\gamma$-H2AX; blue fluorescence, nuclei. (magnification, $\mathrm{x} 200$ ) (B) Statistical analysis of the average percentages of $\gamma$-H2AX-positive U-87 MG cells. (C) Statistical analysis of the average number of $\gamma$-H2AX foci per U-87 MG cell. (D) Statistical analysis of the average percentage of $\gamma$-H2AX-positive U-118 MG cells. (E) Statistical analysis of the average number of $\gamma$-H2AX foci per U-118 MG cell. ${ }^{*} \mathrm{P}<0.05$ and $^{* *} \mathrm{P}<0.01$. Data are the mean \pm standard error of the mean from three independent experiments. DMSO, dimethyl sulfoxide; $\gamma$-H2AX, $\gamma$-histone $\mathrm{H} 2 \mathrm{AX}$.

A
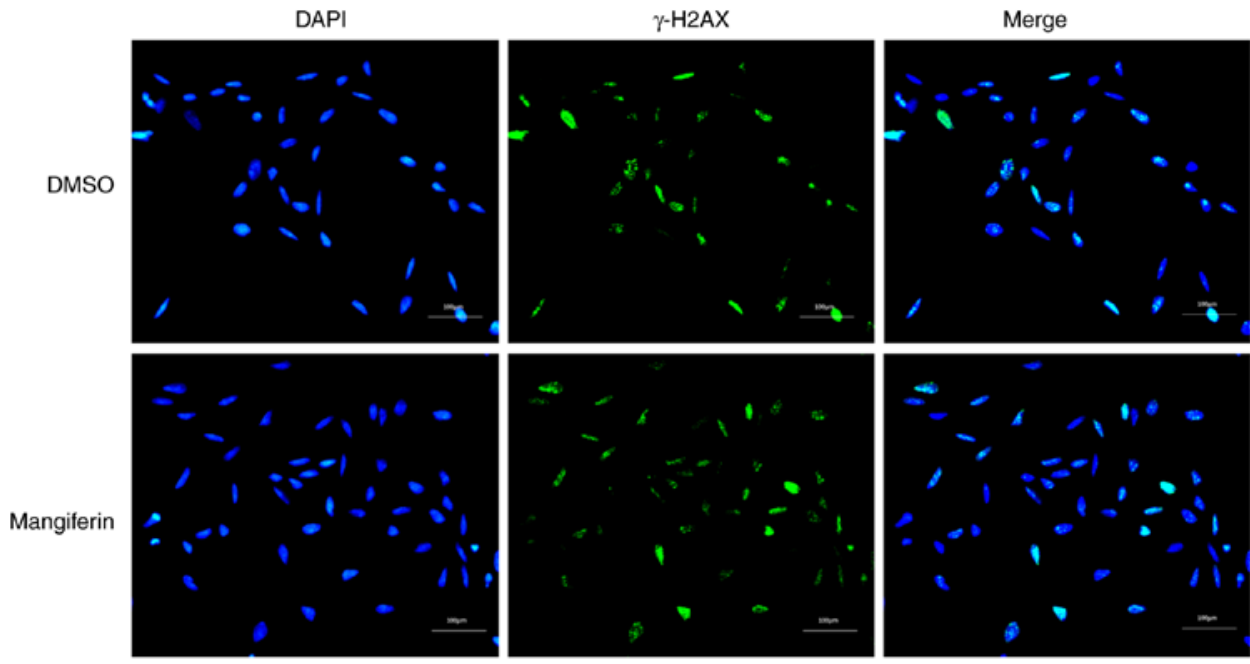

B

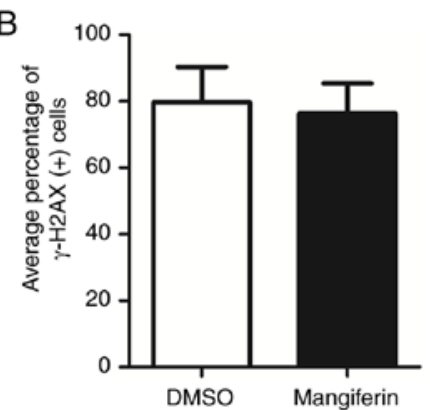

C

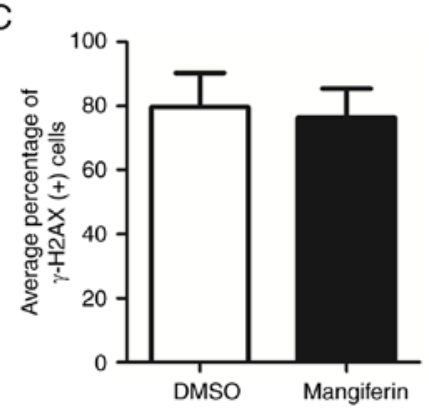

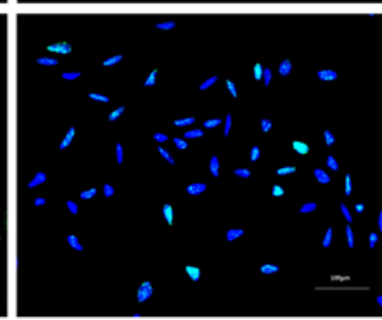

D

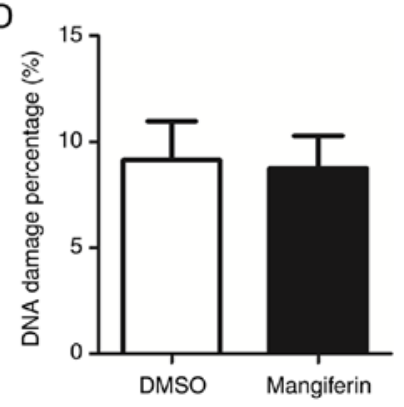

Figure 7. Mangiferin does not inhibit double-strand break repair in rat Schwann cells. (A) Immunofluorescent staining images of Schwann cells treated with mangiferin or DMSO following irradiation. Green fluorescence, $\gamma$-H2AX; blue fluorescence, nuclei. (magnification, x200). (B) Statistical analysis of the average percentages of $\gamma$-H2AX-positive Schwann cells. (C) Statistical analysis of the average number of $\gamma$-H2AX foci per Schwann cell. (D) Statistical analysis of the DNA damage percentages of Schwann cell. Data are the mean \pm standard error of the mean from three independent experiments. DMSO, dimethyl sulfoxide; $\gamma$-H2AX, $\gamma$-histone $\mathrm{H} 2 \mathrm{AX}$.

mangiferin inhibited DNA repair by inhibiting the NHEJ pathway was validated. More importantly, experiments on rat immortalized neuronal Schwann cells revealed that the DSB repair-blocking effect of mangiferin was only triggered in tumor cells. Furthermore, tumor-bearing mouse data indicated that mangiferin was able to increase the sensitivity of the xenograft tumors to IR and maybe a potential therapeutic drug for the treatment of GBM. 
A
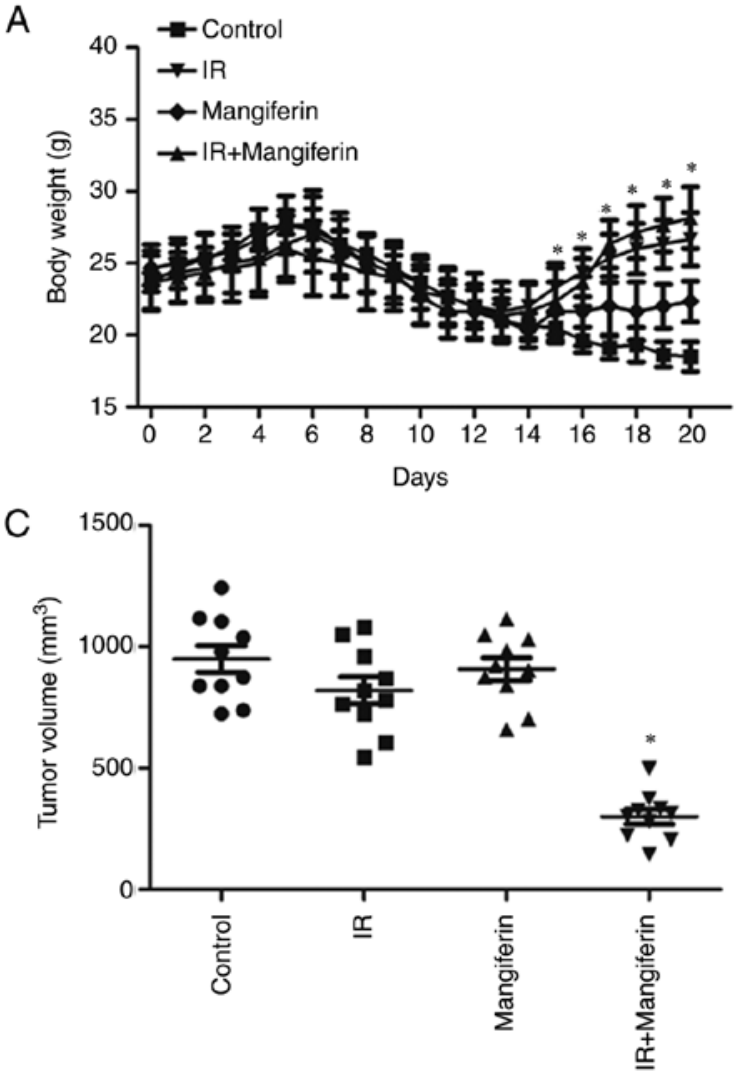

B

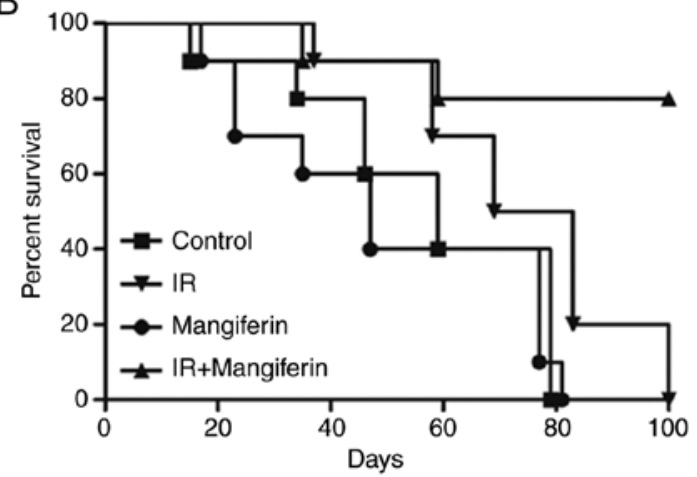

D

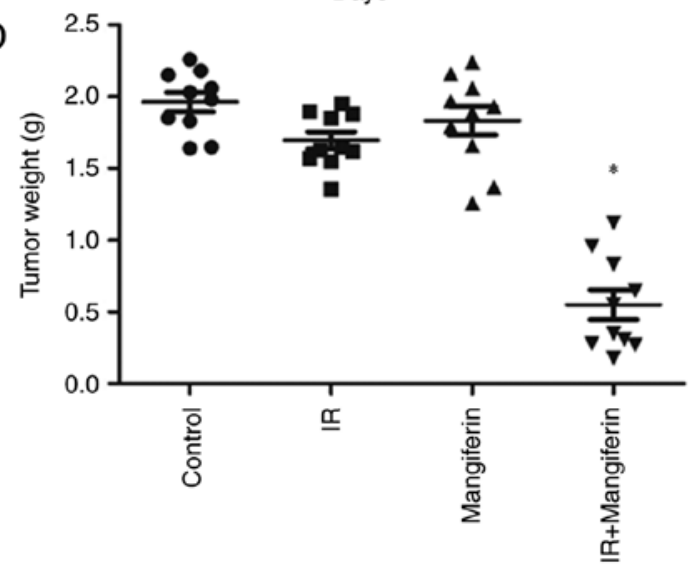

Figure 8. Mangiferin increases the radiosensitivity of xenograft glioblastoma multiforme tumors. (A) Weight changes of U-118 MG cell xenografted mice. $\mathrm{n}=10$. ${ }^{*} \mathrm{P}<0.05$ vs. respective control by two-way analysis of variance with Bonferroni post hoc test. (B) Survival curve of xenograft mice. (C) Relative tumor volume of each group. $\mathrm{n}=10$. $^{*} \mathrm{P}<0.05$ vs. control by one-way analysis of variance with Bonferroni post hoc test. (D) Tumor weights of each group $\mathrm{n}=10$. $\mathrm{P}<0.05$ vs. control by one-way analysis of variance with Bonferroni post hoc test). IR, ionizing radiation.

Previous studies on mangiferin revealed that mangiferin may exert anticancer effects by inhibiting the Notch signaling pathway (27) and transcriptional coactivator YAP1 signaling pathway (He et al, unpublished data) in ovarian cancer. A study on non-small cell lung cancer A549 cells also revealed the anti-neoplastic effects of mangiferin, mediated by inducing apoptosis and cell cycle arrest at the $\mathrm{G}_{2} / \mathrm{M}$ phase (21). Other studies have revealed that mangiferin mediates apoptosis via the activation of nuclear factor- $\mathrm{\kappa B}$ by inducing tumor necrosis factor expression (44). Furthermore, in lung cancer-bearing animals, the activity of glutathione transferase, quinone reductase and uridine 5'-diphosphate-glucuronosyl transferase is enhanced by mangiferin (45). In addition, in K562 cells, mangiferin inhibits telomerase activity and induces apoptosis $(23,24)$. Therefore, mangiferin has been reported to possess anti-neoplastic functions in lung $(19,20)$ and colon cancer $(20,22)$, leukemia $(19,23-26)$, lung $(19,26)$ and prostate cancer (19). However, there exists controversy as to whether mangiferin is able to inhibit the proliferation of GBM cells. According to a study by Pardo Andreu et al (30), mangiferin stimulates the proliferation of human U-138 MG glioblastoma cells. However, a study by Xiao et al (28) demonstrated the increased apoptosis of U-87 MG cells mediated by mangiferin. Furthermore, doubts have been raised about U-87 MG cells originating from the ATCC due to potential contamination (31). Therefore, in the present study, U-87 MG s and U-118 MG cells were used. With mock radiation, slightly inhibited proliferation of mangiferin-treated cells was observed, although this was not statistically significant. This was primarily due to the low concentration used in the present study. In accordance with the study of Xiao et al (28), with the increased concentration of mangiferin, increased apoptosis was also observed in U-87 MG and U-118 MG cells (data not shown). As the primary purpose of the present study was to examine whether mangiferin was able to increase the radiosensitivity of GBM cells, a dosage of $25 \mu \mathrm{g} / \mathrm{ml}$ mangiferin was selected for the present study. With the time course and dose-dependence experiment, the radiosensitive role of mangiferin was observed to be time-and dose-dependent. Further analysis of DNA damage percentages demonstrated that mangiferin-treated GBM cells had more damaged DNA. As there exist two principal pathways of DNA damage repair, the mechanisms underlying mangiferin-inhibited DNA repair required further study.

It has been widely postulated that two principal pathways, NHEJ and HR, are involved in the DSB repair in eukaryotic cells. To facilitate efficient repair, these two principal repair pathways cooperate and compete with each other at DSB sites (46). Although NHEJ appears to compete with HR for DSB, key proteins, including ATM and 53BP1, have been reported to influence HR through a complex regulatory network (39). 53BP1 is a highly conserved DNA damage checkpoint protein, and an important regulator of genome stability by mediating DSB repair (47). A previous study demonstrated that 53BP1-null mice are hypersensitive to radiation due to defects in NHEJ (48). Therefore, to examine the radiosensitive 
role of mangiferin, the phospho-53BP1 expression levels were examined, and decreased activation of 53BP1 mediated by pretreatment with mangiferin was observed. Furthermore, accumulating evidence suggests that ATM serves a critical role in regulating the cellular response to IR (49). A previous study reported that ATM-dependent phosphorylation was a prerequisite for the activation of 53BP1 at DSB sites following IR (12). Therefore, in the present study, it was observed that there was decreased activation of ATM and 53BP1 following treatment with mangiferin and radiation, indicating that mangiferin inhibited DSB repair. In the current study, in order to ensure equal loading, 53BP1 and $\beta$-actin were used as loading controls, and their protein expression was quantified. Furthermore, as previously reported, the activation of ATM in DSB repair also requires the phosphorylation of $\gamma-\mathrm{H} 2 \mathrm{AX}$ and 53BP1 (50). It was observed that there was decreased phosphorylation of $\gamma-\mathrm{H} 2 \mathrm{AX}$ in U-87 MG and U-118 MG cells treated with mangiferin. The formation of $\gamma-\mathrm{H} 2 \mathrm{AX}$ foci was observed in GBM cells treated with either mangiferin or control solvent, and it was identified that mangiferin affected $\gamma$-H2AX phosphorylation and subcellular localization. It may be possible that mangiferin has a phosphatase inhibitor role and directly inhibits the phosphorylation of ATM. It was reported that the SQ/TQ domain is the principal ATM kinase phosphorylation region (51). If mangiferin directly inhibits ATM phosphorylation, it may be possible that mangiferin binds to the SQ/TQ domain and that this binding inhibits ATM phosphorylation. There also exists the possibility that mangiferin indirectly inhibits the phosphorylation of ATM by the inhibition of upstream genes of ATM. Thus, further studies examining the molecular mechanism of mangiferin-inhibited ATM phosphorylation are required. It has been reported that ATM phosphorylates a broad range of substrates, including 53BP1 and $\gamma$-H2AX (52), thus it may be possible that mangiferin phosphorylates ATM at the SQ/TQ domain, and the p-ATM further phosphorylated 53BP1 and $\gamma$-H2AX. Therefore, mangiferin may also directly phosphorylate 53BP1 at the SQ/TQ domain. In order to unravel the molecular mechanisms of the mangiferin-induced phosphorylation of ATM, 53BP1 and $\gamma-\mathrm{H} 2 \mathrm{AX}$, further experiments are required. To confirm the role of NHEJ repair in mangiferin-mediated inhibition of DSB repair following radiation, an in vivo assay system was generated, measuring NHEJ repair using a linearized plasmid (53). By using the NHEJ-I SceI assay system, a markedly decreased NHEJ percentage was observed in U-87 MG cells treated with mangiferin. To evaluate whether the inhibition of DSB repair by mangiferin was mediated only by the inhibition of NHEJ, an HR-I SceI assay system was also generated, and a significant difference in HR repair percentages between mangiferin-treated and DMSO-treated cells was not observed. The present data supported an inhibitory role of mangiferin in NHEJ repair following radiation. The present study subsequently assessed whether mangiferin was able to mediate neuronal protection from IR. Data from rat immortalized Schwann cells revealed that treatment with mangiferin did not result in any alteration in DSB repair. Prior to this, to the best of our knowledge, there had been no direct evidence of the mechanisms underlying the different effects of mangiferin on radiosensitivity between Schwann and GBM cells. A previous study indicated that $5-25 \mu \mathrm{g} / \mathrm{ml}$ mangiferin protected against $\gamma$-radiation-induced DNA damage in human lymphocytes (40). It has also been reported that mangiferin reduces etoposide-induced DNA damage in human umbilical cord blood cells, by inducing the nuclear accumulation of nuclear factor erythroid 2-related factor 2 (Nrf2) and increasing the expression of $\mathrm{NAD}(\mathrm{P}) \mathrm{H}$ dehydrogenase [quinone] 1, a downstream target gene of the Nrf2 pathway (41). Furthermore, the in vitro experiments by Lei et al (54) demonstrated that pretreatment with either mangiferin aglycone or mangiferin was able to inhibit DNA damage by IR in human intestinal epithelial cells. Therefore, it was hypothesized that for normal cells, which are less proliferative compared with tumor cells, mangiferin serves a DNA damage-protective role via its antioxidant function. However, for proliferative tumor cells, mangiferin may increase the radiosensitivity. Another reason may be the crosstalk between metabolism and DNA damage repair. According to the Warburg effect, the majority of cancer cells predominantly produce their energy through aerobic glycolysis; whereas, normal cells primarily produce energy through mitochondrial oxidative phosphorylation (43). Pyruvate kinase PKM (PKM2) has been reported to be the key enzyme in the Warburg effect in tumor cells, and it is not expressed in healthy tissues (44). However, PKM2 also interacts with DNA damage-associated proteins and regulates the DSB repair pathway $(45,46)$. Recent studies revealed a modulating function of mangiferin on the metabolism of carbohydrates and lipids (47). Therefore, it was postulated that by regulating tumor metabolism enzyme PKM2, which exhibits crosstalk with DNA repair pathways, mangiferin may have different DNA damage repair functions in tumor cells and normal cells. However, these assumptions require further examination in future studies. Therefore, mangiferin may possess dual roles by increasing the radiosensitivity of glioblastoma cells and enhancing neuronal protection for normal neuronal cells.

Subsequently, the present study examined the in vivo radiosensitivity of mangiferin in tumor-bearing nude mice. Although complete tumor regression did not occur in all mice, mice treated with mangiferin exhibited significantly smaller tumors with lower tumor weights. As the primary purpose of this study was to examine whether mangiferin was able to prolong the life span of xenograft mice, the survival study was of critical importance. As predicted, mice treated with mangiferin exhibited increased survival following radiation, compared with mice treated with radiation alone. Therefore, mangiferin increased the sensitivity of glioblastoma cells to IR in vivo. Furthermore, no adverse effects were observed, including diarrhea or symptoms of decreased food intake. It has previously been reported that there is no clinical evidence of adverse effects of mangiferin (55). In summary, the present data demonstrated that the radioresistance of GBM cells may be reversed by mangiferin. Therefore, with the marked radiosensitization of GBM cells at low concentrations and neuroprotection of neuronal cells during cranial IR, mangiferin has potential as a novel drug for the treatment of human glioblastoma.

\section{Acknowledgements}

Not applicable. 


\section{Funding}

The present study was supported by the Sichuan Health and Family Planning Commission Funding (grant no. 16ZD0253), the Sichuan Science and Technology Funding (grant no. 2018JY0645), the Funding from Sichuan Academy of Medical Science \& Sichuan Provincial People's Hospital, and Sichuan Scientific Research Foundation of the Returned Overseas Chinese Scholars and the National Science Funding of China (no. 81802504) for YW. The present study was also supported by Sichuan National Science Research Funding (grant no. 2014FZ0126) for RT. The present study was also supported by the National Key Specialty Construction Project of Clinical Pharmacy (grant no. 30305030698).

\section{Availability of data and materials}

The datasets used and analyzed during the current study are available from the corresponding author on reasonable request.

\section{Authors' contributions}

YW, SD and RT designed the study.FM, TLi and HZ performed the molecular and cell experiments. XX performed the animal experiments. TLe generated the plasmids. XH performed the statistical analysis. FM and SD were principal contributors to the production of the figures and writing the manuscript. All authors read and approved the final manuscript.

\section{Ethics approval and consent to participate}

Animal handling was approved by the Ethics Committee of Sichuan Academy of Medical Science and Sichuan Provincial People's Hospital (Chengdu, China).

\section{Patient consent for publication}

Not applicable.

\section{Competing interests}

The authors declare that they have no competing interests.

\section{References}

1. Killock D: CNS cancer: Molecular classification of glioma. Nat Rev Clin Oncol 12: 502, 2015.

2. Walker MD, Alexander E Jr, Hunt WE, MacCarty CS, Mahaley MS Jr, Mealey J Jr, Norrell HA, Owens G, Ransohoff J, Wilson CB, et al: Evaluation of BCNU and/or radiotherapy in the treatment of anaplastic gliomas. A cooperative clinical trial J Neurosurg 49: 333-343, 1978.

3. Debus J and Abdollahi A: For the next trick: New discoveries in radiobiology applied to glioblastoma. Am Soc Clin Oncol Educ Book: e95-e99, 2014.

4. Fan QW and Weiss WA: Targeting the RTK-PI3K-mTOR axis in malignant glioma: Overcoming resistance. Curr Top Microbiol Immunol 347: 279-296, 2010.

5. El-Deiry WS: The role of p53 in chemosensitivity and radiosensitivity. Oncogene 22: 7486-7495, 2003.

6. Bao S, Wu Q, McLendon RE, Hao Y, Shi Q, Hjelmeland AB, Dewhirst MW, Bigner DD and Rich JN: Glioma stem cells promote radioresistance by preferential activation of the DNA damage response. Nature 444: 756-760, 2006.
7. King HO, Brend T, Payne HL, Wright A, Ward TA, Patel K, Egnuni T, Stead LF, Patel A, Wurdak H, et al: RAD51 is a selective DNA repair target to radiosensitize glioma stem cells. Stem Cell Reports 8: 125-139, 2017.

8. van Gent DC, Hoeijmakers JH and Kanaar R: Chromosomal stability and the DNA double-stranded break connection. Nat Rev Genet 2: 196-206, 2001.

9. Dobbs TA, Tainer JA and Lees-Miller SP: A structural model for regulation of NHEJ by DNA-PKcs autophosphorylation. DNA Repair 9: 1307-1314, 2010.

10. Wang H, Perrault AR, Takeda Y, Qin W, Wang H and Iliakis G: Biochemical evidence for $\mathrm{Ku}$-independent backup pathways of NHEJ. Nucleic Acids Res 31: 5377-5388, 2003.

11. Dimitrova N, Chen YC, Spector DL and de Lange T: 53BP1 promotes non-homologous end joining of telomeres by increasing chromatin mobility. Nature 456: 524-528, 2008.

12. DiTullio RA Jr, Mochan TA, Venere M, Bartkova J, Sehested M, Bartek $J$ and Halazonetis TD: 53BP1 functions in an ATM-dependent checkpoint pathway that is constitutively activated in human cancer. Nat Cell Biol 4: 998-1002, 2002.

13. Lieber MR, Ma Y, Pannicke U and Schwarz K: Mechanism and regulation of human non-homologous DNA end-joining. Nat Rev Mol Cell Biol 4: 712-720, 2003.

14. Sánchez GM, Re L, Giuliani A, Núñez-Sellés AJ, Davison GP and León-Fernández OS: Protective effects of Mangifera indica $\mathrm{L}$. extract, mangiferin and selected antioxidants against TPA-induced biomolecules oxidation and peritoneal macrophage activation in mice. Pharmacol Res 42: 565-573, 2000.

15. Guha S, Ghosal S and Chattopadhyay U: Antitumor, immunomodulatory and anti-HIV effect of mangiferin, a naturally occurring glucosylxanthone. Chemotherapy 42: 443-451, 1996.

16. Duang XY, Wang Q, Zhou XD and Huang DM: Mangiferin: A possible strategy for periodontal disease to therapy. Med Hypotheses 76: 486-488, 2011.

17. Wang HL, Li CY, Zhang B, Liu YD, Lu BM, Shi Z, An N, Zhao LK, Zhang JJ, Bao JK, et al: Mangiferin facilitates islet regeneration and $\beta$-cell proliferation through upregulation of cell cycle and $\beta$-cell regeneration regulators. Int J Mol Sci 15: 9016-9035, 2014.

18. Wang H, He X, Lei T, Liu Y, Huai G, Sun M, Deng S, Yang H, Tong $\mathrm{R}$ and Wang $\mathrm{Y}$ : Mangiferin induces islet regeneration in aged mice through regulating $\mathrm{p} 16^{\mathrm{INK} 4 \mathrm{a}}$. Int $\mathrm{J}$ Mol Med 41: 3231-3242, 2018.

19. Garcia-Rivera D, Delgado R, Bougarne N, Haegeman G and Berghe WV: Gallic acid indanone and mangiferin xanthone are strong determinants of immunosuppressive anti-tumour effects of Mangifera indica L. bark in MDA-MB231 breast cancer cells. Cancer Lett 305: 21-31, 2011.

20. Noratto GD, Bertoldi MC, Krenek K, Talcott ST, Stringheta PC and Mertens-Talcott SU: Anticarcinogenic effects of polyphenolics from mango (Mangifera indica) varieties. J Agric Food Chem 58: 4104-4112, 2010.

21. Shi W, Deng J, Tong R, Yang Y, He X, Lv J, Wang H, Deng S, Qi P, Zhang D, et al: Molecular mechanisms underlying mangiferin-induced apoptosis and cell cycle arrest in A549 human lung carcinoma cells. Mol Med Rep 13: 3423-3432, 2016.

22. Chieli E, Romiti N, Rodeiro I and Garrido G: In vitro effects of Mangifera indica and polyphenols derived on ABCB1/ P-glycoprotein activity. Food Chem Toxicol 47: 2703-2710, 2009.

23. Cheng P, Peng ZG, Yang J and Song SJ: The effect of mangiferin on telomerase activity and apoptosis in leukemic K562 cells. Zhong Yao Cai 30: 306-309, 2007 (In Chinese).

24. Peng ZG, Luo J, Xia LH, Chen Y and Song SJ: CML cell line K562 cell apoptosis induced by mangiferin. Zhongguo Shi Yan Xue Ye Xue Za Zhi 12: 590-594, 2004 (In Chinese).

25. Percival SS, Talcott ST, Chin ST, Mallak AC, Lounds-Singleton A and Pettit-Moore J: Neoplastic transformation of BALB/3T3 cells and cell cycle of HL-60 cells are inhibited by mango (Mangifera indica L.) juice and mango juice extracts. J Nutri 136: 1300-1304, 2006.

26. Chari NS, Pinaire NL, Thorpe L, Medeiros LJ, Routbort MJ and McDonnell TJ: The p53 tumor suppressor network in cancer and the therapeutic modulation of cell death. Apoptosis 14: 336-347, 2009.

27. Zou B, Wang H, Liu Y, Qi P,Lei T, Sun M and Wang Y: Mangiferin induces apoptosis in human ovarian adenocarcinoma OVCAR3 cells via the regulation of Notch3. Oncol Rep 38: 1431-1441, 2017.

28. Xiao J, Liu L, Zhong Z, Xiao C and Zhang J: Mangiferin regulates proliferation and apoptosis in glioma cells by induction of microRNA-15b and inhibition of MMP-9 expression. Oncol Rep 33: 2815-2820, 2015. 
29. Jung JS, Jung K, Kim DH and Kim HS: Selective inhibition of MMP-9 gene expression by mangiferin in PMA-stimulated human astroglioma cells: Involvement of PI3K/Akt and MAPK signaling pathways. Pharmacol Res 66: 95-103, 2012.

30. Pardo Andreu GL, Maurmann N, Reolon GK, de Farias CB Schwartsmann G, Delgado R and Roesler R: Mangiferin, a naturally occurring glucoxilxanthone improves long-term object recognition memory in rats. Eur J Pharmacol 635: 124-128, 2010

31. Allen M, Bjerke M, Edlund H, Nelander S and Westermark B: Origin of the U87MG glioma cell line: Good news and bad news. Sci Transl Med 8: 354re3, 2016.

32. Capes-Davis A, Theodosopoulos G, Atkin I, Drexler HG, Kohara A, MacLeod RA, Masters JR, Nakamura Y, Reid YA, Reddel RR, et al: Check your cultures! A list of cross-contaminated or misidentified cell lines. Int J Cancer 127: 1-8, 2010.

33. Boyé K, Pujol N, D Alves I, Chen YP, Daubon T, Lee YZ, Dedieu S, Constantin M, Bello L, Rossi M, et al: The role of CXCR3/LRP1 cross-talk in the invasion of primary brain tumors. Nat Commun 8: 1571, 2017.

34. Volpin F, Casaos J, Sesen J, Mangraviti A, Choi J, Gorelick N, Frikeche J, Lott T, Felder R, Scotland SJ, et al: Use of an anti-viral drug, Ribavirin, as an anti-glioblastoma therapeutic. Oncogene 36: 3037-3047, 2017

35. Yang Y, Lei T, Du S, Tong R, Wang H, Yang J, Huang J, Sun M, Wang Y and Dong Z: Nuclear GSK3 3 induces DNA double-strand break repair by phosphorylating 53BP1 in glioblastoma. Int J Oncol 52: 709-720, 2018

36. Valavanidis A, Vlachogianni T and Fiotakis C: 8-hydroxy-2 -deoxyguanosine (8-OHdG): A critical biomarker of oxidative stress and carcinogenesis. J Environ Sci Health C, Environ Carcinog Ecotoxicol Rev 27: 120-139, 2009.

37. Zhang Q, Karnak D, Tan M, Lawrence TS, Morgan MA and Sun Y: FBXW7 facilitates nonhomologous end-joining via K63-linked polyubiquitylation of XRCC4. Mol Cell 61: 419-433, 2016.

38. Mao Z, Jiang Y, Liu X, Seluanov A and Gorbunova V: DNA repair by homologous recombination, but not by nonhomologous end joining, is elevated in breast cancer cells. Neoplasia 11: 683-691, 2009

39. Shrivastav M, De Haro LP and Nickoloff JA: Regulation of DNA double-strand break repair pathway choice. Cell Res 18: 134-147, 2008.

40. Ricard D, Idbaih A, Ducray F, Lahutte M, Hoang-Xuan K and Delattre JY: Primary brain tumours in adults. Lancet 379 : 1984-1996, 2012.

41. Gil del Alcazar CR, Hardebeck MC, Mukherjee B, Tomimatsu N, Gao X, Yan J, Xie XJ, Bachoo R, Li L, Habib AA and Burma S: Inhibition of DNA double-strand break repair by the dual $\mathrm{PI} 3 \mathrm{~K} / \mathrm{mTOR}$ inhibitor NVP-BEZ235 as a strategy for radiosensitization of glioblastoma. Clin Cancer Res 20: 1235-1248, 2014

42. Gursoy-Yuzugullu O, Carman C, Serafim RB, Myronakis M, Valente V and Price BD: Epigenetic therapy with inhibitors of histone methylation suppresses DNA damage signaling and increases glioma cell radiosensitivity. Oncotarget 8: 24518-24532, 2017.
43. Maachani UB, Kramp T, Hanson R, Zhao S, Celiku O, Shankavaram U, Colombo R, Caplen NJ, Camphausen K and Tandle A: Targeting MPS1 enhances radiosensitization of human glioblastoma by modulating DNA repair proteins. Mol Cancer Res 13: 852-862, 2015.

44. Sarkar A, Sreenivasan Y, Ramesh GT and Manna SK: beta-D-Glucoside suppresses tumor necrosis factor-induced activation of nuclear transcription factor kappaB but potentiates apoptosis. J Biol Chem 279: 33768-33781, 2004.

45. Rajendran P, Ekambaram G and Sakthisekaran D: Protective role of mangiferin against Benzo(a)pyrene induced lung carcinogenesis in experimental animals. Biol Pharm Bull 31: 1053-1058, 2008.

46. Kass EM and Jasin M: Collaboration and competition between DNA double-strand break repair pathways. FEBS Lett 584: 3703-3708, 2010.

47. Abraham RT: Checkpoint signalling: Focusing on 53BP1. Nat Cell Biol 4: E277-E279, 2002.

48. Ward IM, Minn K, van Deursen J and Chen J: p53 Binding protein 53BP1 is required for DNA damage responses and tumor suppression in mice. Mol Cell Biol 23: 2556-2563, 2003.

49. Kurz EU and Lees-Miller SP: DNA damage-induced activation of ATM and ATM-dependent signaling pathways. DNA Repair 3: 889-900, 2004

50. Riballo E, Kühne M, Rief N, Doherty A, Smith GC, Recio MJ, Reis C, Dahm K, Fricke A, Krempler A, et al: A pathway of double-strand break rejoining dependent upon ATM, Artemis, and proteins locating to gamma-H2AX foci. Mol Cell 16: 715-724, 2004.

51. Traven A and Heierhorst J: SQ/TQ cluster domains: Concentrated ATM/ATR kinase phosphorylation site regions in DNA-damageresponse proteins. Bioessays 27: 397-407, 2005.

52. Fernandez-Capetillo O, Chen HT, Celeste A, Ward I, Romanienko PJ, Morales JC, Naka K, Xia Z, Camerini-Otero RD, Motoyama $\mathrm{N}$, et al: DNA damage-induced $\mathrm{G}_{2}-\mathrm{M}$ checkpoint activation by histone H2AX and 53BP1. Nat Cell Biol 4: 993-997, 2002.

53. Mukherjee B, Tomimatsu N, Amancherla K, Camacho CV, Pichamoorthy $\mathrm{N}$ and Burma S: The dual PI3K/mTOR inhibitor NVP-BEZ235 is a potent inhibitor of ATM- and DNA-PKCs-mediated DNA damage responses. Neoplasia 14: 34-43, 2012.

54. Lei J, Zhou C, Hu H, Hu L, Zhao M, Yang Y, Chuai Y, Ni J and Cai J: Mangiferin aglycone attenuates radiation-induced damage on human intestinal epithelial cells. J Cell Biochem 113: 2633-2642, 2012.

55. Guo HW, Yun CX, Hou GH, Du J, Huang X, Lu Y, Keller ET, Zhang J and Deng JG: Mangiferin attenuates TH1/TH2 cytokine imbalance in an ovalbumin-induced asthmatic mouse model. PLoS One 9: e100394, 2014. 